\title{
PRÁTICAS DE GESTÃO ESTRATÉGICA DE CUSTOS: UM ESTUDO EM UMA EMPRESA MULTINACIONAL BRASILEIRA
}

\author{
PRACTICES OF STRATEGIC COST MANAGEMENT IN A BRAZILIAN \\ MULTINATIONAL COMPANY
}

\author{
MARCOS ANTONIO SOUZA \\ Professor da Universidade do Vale do Rio dos Sinos, UNISINOS \\ Doutorado em Controladoria e Contabilidade pela Universidade de São Paulo. \\ Doutorado em Controladoria e Contabilidade pela Unive
São Leopoldo, RS - Brasil
E-mail: souza.marcosas@gmail.com
}
ÉLIO JUSTO SILVA
Mestrando em Ciências Contábeis pela
Universidade do Vale do Rio dos Sinos, UNISINOS
São Leopoldo, RS - Brasil

\author{
NESTOR PILZ \\ Mestrando em Ciências Contábeis pela
Universidade do Vale do Rio dos Sinos, UNISINOS \\ São Leopoldo, RS - Brasil \\ E-mail: nestor@unisinos.br
}

\section{RESUMO}

Em um ambiente marcado por acirrada disputa de mercado, as práticas de gestão estratégica de custos - GEC surgem como instrumentos que podem colaborar para que as empresas consigam assegurar a vantagem competitiva. Nesse contexto, o objetivo deste artigo é identificar quais formatações e práticas da GEC têm estado presente na gestão empresarial. Essa busca de referendar na prática os mais recentes desenvolvimentos teóricos foi conduzida por meio de uma pesquisa exploratória, de características qualitativas e descritivas, cuja coleta de dados deu-se por entrevista em profundidade realizada com o controller de uma indústria química brasileira sediada no Vale do Rio dos Sinos - RS, e com expressiva presença internacional. Os principais achados da pesquisa, realizada no terceiro trimestre de 2009, indicam, contrariamente ao que preceitua a literatura, haver acentuada preferência pelo uso de tradicionais práticas de gestão de custos, apesar do perfil da empresa pesquisada em atuar com liderança em mercados competitivos. Essas características evidenciam um forte distanciamento em relação aos argumentos e conteúdo da literatura recente que trata da gestão de custos. A não identificação objetiva dos possíveis benefícios bloqueia a adoção de práticas da GEC, tais como o $A B C$, o $A B M$, o custo-meta e o custo total de uso e propriedade.

Palavras-chave: Vantagem Competitiva. Contabilidade Gerencial. Custos. Gestão Estratégica de Custos.

\section{ABSTRACT}

In an environment characterized by intensified competition, the strategic cost management practices - SCM appear as instruments that can collaborate for the companies to reach and maintain the competitive advantage. In this context, this study intends to identify which structure and practices of SCM are present in the enterprise management process. This aim to confirm the effective applying the most recent theoretical developments about SCM was carried out by an exploratory research, of qualitative and descriptive characteristics. Data was collected by depth interview carried out with controller of Brazilian chemical industry located in the Vale do Rio dos Sinos, Rio Grande do Sul State, Brazil, and with expressive international presence. The main results of the research, carried out during the 2009 third quarter, indicate, contrary to the literature, to exist hard preference for the use of traditional procedures of cost accounting management, although the company searched has leadership in competitive markets. These results show a strong contradiction in relation to the arguments and content of the recent literature about cost management practices. The lack of an objective identification of possible benefits from the practices searched block the adoption of SCM practices, such as ABC, ABM, target cost and total cost ownership.

Keywords: Competitive Advantage. Management Accounting. Costs. Strategic Cost Management. 


\section{INTRODUÇÃO}

Conquistar e manter a competitividade de uma empresa é um crescente desafio dos gestores empresariais na atualidade. A literatura acerca do tema propicia metodologias e instrumentos para o desenvolvimento e para a sustentação de um posicionamento estratégico que viabilize superar tal desafio. Porter (1989), Shank e Govindarajan (1995) e Kaplan e Norton (1997), entre outros, são frequentemente citados quanto o tema tratado está ligado à busca de vantagem competitiva.

Um dos instrumentos que colaboram para conquistar e sustentar tal competitividade, conforme destaque dado pela literatura é a gestão estratégica de custos - GEC, cujas práticas surgiram em resposta às críticas sobre a utilidade daquelas até então adotadas pela tradicional contabilidade gerencial (JOHNSON e KAPLAN, 1987; JOHNSON, 1992; BACIC, 1994; MONDEN, 1995, SHANK e GOVINDARAJAN, 1995). O que há em comum nessas abordagens é, além da discussão de práticas específicas, o entendimento de que a gestão de custos passa, também, pela análise dos fatores ambientais externos à empresa. Nesta perspectiva da GEC, os dados e informações da contabilidade gerencial e de custos devem ser mais amplamente considerados. A esse respeito, Hansen e Mowen (2001, p.423), entendem que "a gestão estratégica de custos é o uso de dados de custos para desenvolver e identificar estratégias superiores que produzirão uma vantagem competitiva sustentável."

Esse entendimento de Hansen e Mowen pode ser encontrado em Slagmulder e Cooper (2003), para os quais a gestão estratégica de custos não se resume simplesmente na busca pela redução de custos, mas sim em ações que busquem, simultaneamente a isso, melhorar a vantagem competitiva da empresa em termos amplos. Isso significa gerenciar custos com eficácia, o que exige um enfoque amplo, externo à empresa, pois a análise do ambiente interno, isoladamente, não mais oferece informações suficientes para assegurar a eficácia do processo decisório. Nesse sentido, é preciso reconhecer que em razão do acirramento da competitividade global há necessidade de gerar informações contábeis que deem sustentação ao foco estratégico da empresa, cabendo à contabilidade gerencial cumprir este papel.

Diante de tal realidade, e em decorrência de críticas feitas à contabilidade (JOHNSON e KAPLAN, 1987) surgiu uma série de práticas e procedimentos considerados mais adequados às novas demandas da gestão, entre elas: (a) custeamento e orçamento baseado em atividades; (b) custeamento por ciclo de vida dos produtos; (c) análise de custos da cadeia de valor; (d) maior ênfase nos indicadores não financeiros; (e) análise dos custos de logística interna e de distribuição; (f) gestão dos determinantes de custos; (g) gestão dos custos da qualidade e ambiental; (8) análise dos custos dos concorrentes; (h) gestão interorganizacional de custos; (i) custo-meta, dentre outros.

Pesquisas têm sido realizadas sobre a adoção dessas práticas. Dentre elas têm-se Souza (2001), Bowhill e Lee (2002), Morelli e Wiberg (2002), Dekker e Smidt (2003), Sulaiman, Ahmad e Alwi (2004), Sulaiman, Ahmad e Alwi (2005), Waweru, 
Hoque e Uliana (2005), Souza, Zanella e Nascimento (2005), Cinquini e Tenucci (2006), Rattray, Lord e Shanahan (2007), Quesado e Rodrigues (2007), Reckziegel, Souza e Diehl (2007), De Zoysa e Herath (2007).

Diante desse contexto, o objetivo deste estudo é investigar qual o efetivo uso de algumas dessas práticas de GEC e de como a estrutura das empresas se adaptaram a tais necessidades estratégicas. Pretende-se, a partir dessa investigação, identificar se a realidade da prática empresarial está consistente com os procedimentos recomendados pelos desenvolvimentos teóricos enfatizados na literatura que trata dessas práticas de gestão. Assim, a questão de pesquisa que se apresenta é a seguinte: qual a validade dada pelas empresas quanto ao uso de práticas de GEC recomendadas pela literatura? Para atender este objetivo geral, foram definidos os seguintes objetivos específicos: a) Identificar as principais práticas de gestão de custos e de GEC destacadas na literatura; b) Identificar quais as práticas utilizadas e benefícios alcançados pela empresa; c) Identificar quais as práticas com potencial de uso futuro.

A justificativa deste estudo ampara-se no pronunciamento de diversos pesquisadores. ludícibus (1996) destaca a importância da doutrina contábil, mas reconhece que ela deve ser validada pelos experimentos reais. Gomes (1995) defende o confronto da teoria com a prática para evitar que o senso comum prevaleça na apresentação dos novos enfoques como panacéia para a maioria dos problemas de gestão das organizações. Franco (1999) destaca a validade de pesquisas realizadas com a colaboração das empresas para o avanço no conhecimento da contabilidade gerencial.

Ratificando o entendimento desses autores, as pesquisas sobre a efetiva adoção de práticas de gestão de custos têm dado sua contribuição ao indicar a necessidade de aperfeiçoamentos dos novos modelos. É o caso do surgimento do Time-Driven$A B C$, um novo modelo para adoção do método de custeio baseado em atividades $(A B C)$, cujo redesenho decorreu de pesquisas empíricas realizadas com empresas (KAPLAN e ANDERSON, 2007; VAN DER MERWE, 2009).

Além desta introdução o estudo contém a exposição do referencial teórico pertinente ao tema, seguido da apresentação dos procedimentos metodológicos adotados na pesquisa. Na sequência tem-se a apresentação e a análise dos dados, finalizando com a apresentação das conclusões do estudo e das referências usadas no seu desenvolvimento.

\section{REFERENCIAL TEÓRICO}

\subsection{Gestão Estratégica}

Há uma vasta literatura abordando a globalização, suas origens, os conceitos que a elucidam e as consequências dela para a economia dos países, empresas e demais agentes econômicos. Nesse contexto da globalização, e da consequente expansão dos negócios internacionais, há um desejo comum das empresas, independentemente de suas origens: o de alavancar operações e resultados. A relativa eliminação das 
fronteiras e barreiras na esfera de atuação das empresas, aliada ao expressivo avanço nas tecnologias de produção e comunicação, tem resultado na existência de um mercado cada vez mais competitivo e exigente.

Franco (1999) afirma que com a globalização a competição torna-se mais intensa obrigando a que as empresas sejam mais inovadoras e criativas para manteremse competitivas. Esse entendimento também está presente em Porter (1989), para o qual a empresa competitiva é aquela que adota estratégias que possibilitam estabelecer uma posição lucrativa e sustentável contra as forças que determinam a concorrência.

Nakagawa (1994) também segue essa linha de entendimento ao afirmar que a competitividade da empresa caracteriza-se pela capacidade que ela tem de desenvolver e sustentar vantagens competitivas, capacitando-se a enfrentar a concorrência. É do reconhecimento desse ambiente de acirrada disputa de mercado e da necessidade de um processo organizado de busca pela competitividade que surge a gestão estratégica. Wright, Kroll e Parnell (2000) definem que essa gestão envolve três fases centrais: (a) Formulação da Estratégia, que corresponde ao desenvolvimento da estratégia; (b) Implementação da Estratégia, que significa colocar a estratégia em ação; (c) Controle Estratégico, correspondente a monitorar e modificar a estratégia, ou sua implementação, para assegurar que os resultados desejados sejam alcançados.

Wright, Kroll e Parnell (2000) enfatizam que essa administração estratégica é, na realidade, mais ampla e abrange não somente essas três fases, mas também algumas fases intermediárias que as antecedem, compreendendo a determinação da missão e dos objetivos da organização no contexto de seus ambientes externo e interno. Rocha (1999) trata de algumas dessas fases intermediárias referidas por Wright, Kroll e Parnell (2000), ao que ele denomina de processo de gestão estratégica e o caracteriza como as etapas necessárias para a realização ótima da gestão estratégica, a qual ocorre de forma contínua e não periódica como é feito no planejamento estratégico. As seguintes fases do processo de gestão estratégica são explicitadas por Rocha (1999):

a) Análise do ambiente: a partir da coleta dos dados do ambiente próximo, ocorre a análise e seleção das entidades e variáveis de clientes, fornecedores, concorrentes, consumidores etc.;

b) Concepção de estratégias: é daí que "brotam” as grandes idéias, prevalecendo a criatividade e a inteligência dos executivos;

c) Avaliação ex-ante: nesta etapa realiza-se o julgamento das estratégias concebidas para aprová-las ou rejeitá-las;

d) Desenvolvimento das estratégias aprovadas: realiza a modelagem, o desdobramento em passos menores e a validação das estratégias, definindo datas e valores, sendo que, ainda nesta fase pode-se constatar a viabilidade ou inviabilidade da estratégia aprovada;

e) Implementação das estratégias: é o momento de colocar a estratégia em 
ação. É a etapa de execução, no processo de gestão global de qualquer empreendimento;

f) Avaliação ex-post: é a avaliação após a implementação das estratégias para verificar se os resultados obtidos estão de acordo com o planejado;

g) Feedback: Corresponde ao controle do processo de gestão estratégica, monitorando as estratégias, para sustentar a vantagem competitiva.

Rocha (1999) contribui no esclarecimento do que é gestão estratégica e o faz mediante sua comparação com os tradicionais conceitos do planejamento estratégico (Quadro 1). Por essa comparação é possível identificar que o planejamento estratégico é uma das fases que dão sustentação ao desenvolvimento da gestão estratégica.

\begin{tabular}{|l|l|}
\hline \multicolumn{1}{|c|}{ Planejamento Estratégico } & \multicolumn{1}{c|}{ Gestão Estratégica } \\
\hline É uma fase do processo de gestão & É um processo de gestão \\
\hline $\begin{array}{l}\text { O objetivo é assegurar o cumprimento da missão } \\
\text { e a continuidade da entidade }\end{array}$ & $\begin{array}{l}\text { O objetivo é assegurar a continuidade da } \\
\text { empresa, com vantagem em relação aos } \\
\text { concorrentes. }\end{array}$ \\
\hline Inicia-se com o estabelecimento de cenários & Ocorre sob cenário pré-estabelecido \\
\hline Precede a busca de vantagens competitivas & $\begin{array}{l}\text { Caracteriza-se fortemente pela busca de } \\
\text { vantagens competitiva. }\end{array}$ \\
\hline $\begin{array}{l}\text { O produto final é um conjunto de diretrizes } \\
\text { estratégicas qualitativas (o plano estratégico }\end{array}$ & $\begin{array}{l}\text { E um processo conterinuo, e nána } \\
\text { por um único produto final, formal, pronto e } \\
\text { acabado. }\end{array}$ \\
\hline
\end{tabular}

Quadro 1: Comparação Básica entre Planejamento Estratégico e Gestão Estratégica.

Fonte: Rocha (1999).

Na busca da vantagem competitiva sustentável, talvez o principal foco da gestão estratégica, a contabilidade de custos fornece parte das informações necessárias ao desenvolvimento, implantação e monitoramento das escolhas estratégicas. Esse é um elemento relevante que, na ótica de Shank e Govindarajan (1995), em consistência ao entendimento de Wright, Kroll e Parnell (2000), possibilita que a empresa tenha sustentação e sucesso no desenvolvimento da sua gestão estratégica. Neste processo, as informações contábeis são relevantes quando sistematizadas em relatórios formatados em conformidade com os parâmetros estratégicos (BACIC, 1994).

\subsection{ESTRATÉGIAS GENÉRICAS DE PORTER}

Para Porter (1989) existem dois tipos básicos de vantagem competitiva: baixo custo ou diferenciação. Quando combinados, resultam em três estratégias genéricas para alcançar desempenho superior: liderança de custo, diferenciação e enfoque. Para Motta (1995), uma vantagem competitiva nasce a partir do valor que a empresa cria para seus clientes. Tal vantagem é materializada em menores preços para bens equivalentes ou oferta de bens exclusivos, situação em que a importância do preço é superada pelos benefícios reconhecidos pelos clientes.

Aestratégia de liderança em custoé resultante, principalmente, em permanente 
e disciplinado controle dos custos, no projeto do produto, sua produção, distribuição e assistência pós-venda. O reflexo desse esforço é a manutenção de preço inferior ao dos concorrentes, sem prejuízo da qualidade e dos serviços ao cliente.

A estratégia de diferenciação significa criar uma singularidade para o produto, visando atender clientes com necessidades específicas. Assim, a diferenciação se configura como uma estratégia competitiva capaz de atender as necessidades e preferências de clientes com produtos personalizados, valorizando os seus atributos em preferência do menor preço (MURRAY, 1988). A adoção da estratégia de diferenciação pode ser operacionalizada de várias maneiras: por meio da marca, das especificidades e atributos do produto, de serviços personalizados pré e pós-venda, de alternativas de financiamento, entre outras possibilidades (PORTER, 2004; MURRAY, 1988).

Porter (2004) acrescenta que mesmo aqui neste contexto a empresa deve identificar todas as oportunidades de redução de custo, assim como esgotar todas as possibilidades de diferenciação que não sejam onerosas demais. Acrescenta que apesar de ser impossível ter mais de uma empresa com liderança em custo, é perfeitamente concebível que várias empresas obtenham sucesso com a adoção de estratégia voltada para diferenciação.

A terceira estratégia, conforme Porter (2004) ocorre quando se escolhe como foco um determinado grupo comprador ou um segmento de produtos. Nessa estratégia a empresa deve ser capaz de atender a um público alvo, de forma mais efetiva do que seus concorrentes que competem em nível amplo e que não tem esse foco de atendimento. Ao adotar a estratégia de enfoque a empresa pode atingir a diferenciação por atender melhor as necessidades de seu público-alvo, ou ainda, alcançar a liderança em custos ao enfocar custos mais baixos para atender o nicho desejado.

Hansen e Mowen (2001) esclarecem que muitas empresas na definição do seu posicionamento estratégico não escolhem apenas uma estratégia geral, mas uma combinação ótima das três abordagens estratégicas gerais desenvolvidas por Porter.

\subsection{OS NÍVEIS ORGANIZACIONAIS E A GESTÃO DE CUSTOS}

Antes de aprofundar-se no contexto da GEC é salutar destacar a inter-relação dos níveis organizacionais com a gestão de custos. Num primeiro momento está o contexto da contabilidade de custos (nível operacional), que proporciona informações para a contabilidade gerencial (nível tático) e, que evoluiu para contabilidade estratégica ou gestão estratégica de custos (PEREIRA, ARIMA e KOBAYASHI, 2004).

Nesse sentido, as organizações podem ser divididas em três níveis de influência ou hierarquia, da seguinte forma:

- Nível estratégico: trata, em nível de direção, das macro decisões da organização, tais como a gestão estratégica e o planejamento estratégico;

- Nível tático: trata do nível gerencial da organização, que dá apoio ao nível 
estratégico e coordena as atividades operacionais;

- Nível operacional: trata do nível de execução das atividades fins da organização, onde são realizadas aquelas tarefas mais rotineiras.

\subsection{GESTÃO ESTRATÉGICA DE CUSTOS}

Para Quesado e Rodrigues (2007) a GEC é um processo direcionado à melhoria contínua e à criação de valor para o cliente e que isso é possível por analisar não apenas os processos em que há agregação de valor por parte da empresa, mas na cadeia de produção como um todo. Prado (2004 p.19) enfatiza que "a finalidade principal é fornecer as informações de que as empresas necessitam para proporcionar valor, qualidade e oportunidade que os clientes desejam."

Para Shank e Govindarajan (1995) na GEC a análise é vista sob um contexto mais amplo do o tradicional processo de avaliação do impacto financeiro das decisões gerenciais, e que nela os elementos estratégicos se tornam mais conscientes, explícitos e formais.

Martins (2008), numa exposição mais analítica, enfatiza que a GEC, numa visão mais abrangente implica em análises que incluem o ambiente externo da empresa, ou seja, em toda sua cadeia de valor, o que implica na análise dos custos dos fornecedores, clientes e consumidor final. Portanto, considera todas as fases e oportunidades de redução de custos e de aumento da competitividade.

Para Souza, Bacic e Rabelo (1995) a inclusão do adjetivo estratégico à expressão gestão de custos, assim como o alcance da GEC no desempenho, só podem ser entendidos se situados no contexto de longo prazo e no âmbito das estratégias competitivas das empresas.

Bacic (1994) acrescenta que a competitividade se legitima quando provoca um ganho social e contribui para a melhoria dos fatores estruturais - mercado, fornecedores, produtos substitutos, tecnologia e questões sociais e ambientais. Bacic (1994) complementa que a competitividade da empresa depende do seu posicionamento diante destes fatores, oferecendo de forma duradoura e sustentável maior valor aos clientes, nas suas negociações com os seus fornecedores, no emprego de mão-de-obra qualificada e bem remunerada e na questão da qualidade de produtos e serviços.

\subsubsection{PRINCIPAIS ELEMENTOS DA GESTÃO ESTRATÉGICA DE CUSTOS}

$\mathrm{Na}$ literatura que trata da GEC é recorrente o destaque dos três temas da abordagem de Shank e Govindarajan (1995): análise de cadeia de valor, análise de posicionamento estratégico e análise dos direcionadores de custos. Para Bacic (1994) a originalidade de Shank e Govindarajan está justamente na articulação que eles conseguem realizar com os três tópicos, analisando-os em temas relativos a custos. 
O primeiro tema, a cadeia de valor, explora os elos da empresa com seus fornecedores e clientes, um reconhecimento de que a gestão interna de custos, isoladamente, não é mais suficiente para o alcance da vantagem competitiva. Ignorar tal abrangência é assumir riscos além dos necessários e implícitos à atividade empresarial (HANSEN e MOWEN, 2001; BACIC, 1994; MACHADO e SOUZA, 2006).

O segundo tema, o posicionamento estratégico, é dependente, também, das informações que se tem sobre o ambiente externo. Porter (1989) faz explícita menção a esse respeito quando trata das estratégias competitivas genéricas e das cinco forças que dirigem a concorrência. Por mais que tais elementos do posicionamento estratégico possam ter suas limitações, conforme abordado por Greenwald e Kahn (2006), é reconhecido que as informações de custos integram o processo dessa gestão estratégica, em todas as suas três fases - formulação, implementação e controle da execução estratégica (BACIC, 1994).

Por fim o terceiro tema, os direcionadores de custos, também tratados por determinantes de custos (ROCHA, 1999), são os fatores causais no consumo dos recursos. No custeio baseado em atividades o direcionador é a atividade que causa o custo. Na gestão estratégica de custos o conceito é mais abrangente e decorre das alternativas de estratégia adotadas pela empresa.

Shank e Govindarajan (1995) os classifica em duas categorias:

- (a) direcionadores estruturais: relacionam-se com a estrutura econômica estabelecida pela organização para desenvolver suas atividades;

- (b) direcionadores operacionais ou de execução: relacionam-se com o desempenho da organização e reflete a capacidade dela em utilizar a estrutura na realização das atividades.

Miotto (2007) desenvolve sua pesquisa nessa mesma linha de entendimento dos determinantes de custos e oferece uma análise detalhada e exemplificada de cada um dos componentes que formam essas duas categorias.

\subsubsection{PRÁTICAS DA GESTÃO ESTRATÉGICA DE CUSTOS}

Os parâmetros para discernir acerca das práticas de contabilidade estratégica e de GEC conforme apresentado por Guilding, Cravens e Tayles (2000), são:

(a) estejam orientadas para o mercado ou o ambiente externo;

(b) tenham o foco sobre os competidores;

(c) tenham orientação temporal para o futuro de longo prazo.

Tais parâmetros estão presentes nas práticas de GEC, consideradas na literatura como mais apropriadas para a gestão estratégica das empresas, tem sido objeto de diversas pesquisas empíricas conforme destacado na Introdução do estudo.

Consta do Quadro 2 as principais práticas, acompanhadas da sumária indicação 
dos atributos principais.

\begin{tabular}{|c|c|}
\hline Prática de GEC & Atributo Principal \\
\hline $\begin{array}{l}\text { ABC/M Custeio/Gestão } \\
\text { Baseada em Atividades }\end{array}$ & $\begin{array}{c}\text { Práticas desenvolvidas para o custeio e gerenciamento das } \\
\text { atividades que consomem recursos; permitem a mensuração, } \\
\text { identificação, redução ou até eliminação das atividades que não } \\
\text { geram valor ao cliente. }\end{array}$ \\
\hline Custeio de Atributos & $\begin{array}{c}\text { Prática para custeio que considera os atributos dos produtos como } \\
\text { objeto de custeio; custeia os atributos que diferenciam os produtos } \\
\text { em relação às preferências clientes. }\end{array}$ \\
\hline Benchmarking & $\begin{array}{l}\text { Prática de melhoria mediante a identificação e análise comparativa } \\
\text { das melhores práticas de gestão de mercado. }\end{array}$ \\
\hline $\begin{array}{l}\text { Monitoramento da Posição } \\
\text { Competitiva }\end{array}$ & $\begin{array}{c}\text { Prática da coleta de informações sobre concorrentes relacionadas a } \\
\text { vendas, custos, produtos e participação de mercados. }\end{array}$ \\
\hline $\begin{array}{l}\text { Estimativa do Custo da } \\
\text { Concorrência }\end{array}$ & $\begin{array}{c}\text { Prática de coleta indireta e de estimativa sobre o custo dos } \\
\text { concorrentes, com base em clientes e fornecedores comuns e outras } \\
\text { técnicas específicas. }\end{array}$ \\
\hline $\begin{array}{l}\text { Avaliação dos } \\
\text { Concorrentes com Base nas } \\
\text { Demonstrações Contábeis } \\
\text { publicadas }\end{array}$ & $\begin{array}{l}\text { Prática da análise das demonstrações contábeis dos concorrentes } \\
\text { como fonte de avaliação das respectivas performance econômico- } \\
\text { financeira. }\end{array}$ \\
\hline Contabilidade de Clientes & $\begin{array}{l}\text { Prática de análise das demonstrações contábeis dos clientes com } \\
\text { fonte de avaliação da performance econômico-financeira. }\end{array}$ \\
\hline $\begin{array}{l}\text { Mensuração Integrada de } \\
\text { Desempenho (BSC) }\end{array}$ & $\begin{array}{l}\text { Prática de avaliação integrada de desempenho, com medidas } \\
\text { financeiras e não financeiras, na perspectiva do aprendizado e } \\
\text { crescimento, dos processos internos, dos clientes e financeira. }\end{array}$ \\
\hline Custeio do Ciclo de Vida & $\begin{array}{l}\text { Prática de avaliação do custo total dos produtos ao longo das fases } \\
\text { do seu ciclo de vida; concepção, produção, distribuição, consumo e } \\
\text { descarte. }\end{array}$ \\
\hline Custeio da Qualidade & $\begin{array}{c}\text { Prática de monitoramento de custos da qualidade de produtos e } \\
\text { serviços, inclusive as decorrentes de falhas internas (retrabalho e } \\
\text { sucatas) e externas (devoluções e garantias). }\end{array}$ \\
\hline $\begin{array}{l}\text { Custeio e Precificação } \\
\text { Estratégicos }\end{array}$ & $\begin{array}{l}\text { Prática de custeio do posicionamento de mercado e busca da } \\
\text { vantagem competitiva e reações dos concorrentes a mudanças de } \\
\text { preços. }\end{array}$ \\
\hline $\begin{array}{l}\text { Custeio-Meta (ou Custo- } \\
\text { Alvo }\end{array}$ & $\begin{array}{l}\text { Prática de determinação do custo aceitável, calculado a partir de } \\
\text { preço de venda aceitável pelo mercado menos o lucro desejado. }\end{array}$ \\
\hline Custeio da Cadeia de Valor & $\begin{array}{c}\text { Prática de monitoramento das oportunidades existentes nos vínculos } \\
\text { externos com clientes e fornecedores. }\end{array}$ \\
\hline Análise de Custo Intangível & $\begin{array}{c}\text { Prática de análise de custos ocultos fruto de itens estruturais } \\
\text { e ineficiência de gestão; decorrem da existência de fatores } \\
\text { intangíveis e resultantes da formação de ativos intangíveis, como a } \\
\text { competência para a inovacão. }\end{array}$ \\
\hline Análise de Custo Ambiental & $\begin{array}{l}\text { Prática de análise dos custos decorrentes da busca ou falta } \\
\text { da ecoeficiência ambiental, em atividades de recuperação, } \\
\text { monitoramento e reciclagem de produtos e resíduos. }\end{array}$ \\
\hline Análise de Custo Logístico & $\begin{array}{l}\text { Prática de análise dos custos de abastecimento, aquisição, } \\
\text { distribuição e armazenagem de insumos e produtos. }\end{array}$ \\
\hline Analise de Custo Kaizen & $\begin{array}{l}\text { Prática de análise com foco na melhoria contínua de processos para } \\
\text { a redução de custos durante o ciclo de vida do produto. }\end{array}$ \\
\hline
\end{tabular}

Quadro 2: Práticas de Gestão Estratégica de Custos

Fonte: Construído a partir de Cinquini e Tenucci (2006). 
Cinquini e Tenucci (2006), em pesquisa junto a 93 empresas italianas que responderam ao questionário sobre a utilização de 14 práticas de GEC, revelaram que custeio de atributos, contabilidade de clientes, precificação estratégica e monitoramento da posição competitiva foram as de mais largo uso; as menos indicadas foram as práticas do custeio do ciclo de vida e mensuração integrada de desempenho (BSC).

Com base no estudo de Cinquini e Tenucci (2006) são relacionadas as práticas em relação técnicas aos fatores/focos de referencia, divididas em três grupos: Concorrentes, Futuro, Processos e Atividades ou Clientes (Quadro 3).

\begin{tabular}{|c|l|}
\hline Fatores de Referência & \multicolumn{1}{|c|}{ Práticas de Gestão Estratégica de Custos } \\
\hline Concorrentes & $\begin{array}{l}\text { Estimativa de Custo do Concorrente; } \\
\text { Análise de Demonstrações Contábeis do Concorrente; } \\
\text { Monitoramento da Posição Competitiva; } \\
\text { Precificação Estratégica; } \\
\text { Benchmarking. }\end{array}$ \\
\hline Futuro (Longo Prazo) & $\begin{array}{l}\text { Custeio da Qualidade; } \\
\text { Custeio do Ciclo de Vida; } \\
\text { Custeio Estratégico. }\end{array}$ \\
\hline Processos e Atividades & $\begin{array}{l}\text { ABC/ABM; } \\
\text { Custeio da Cadeia de Valor } \\
\text { Custeio Alvo ou Meta } \\
\text { Mensuração de Desempenho Integrado (BSC) }\end{array}$ \\
\hline Clientes & $\begin{array}{l}\text { Custeio de Atributos } \\
\text { Análise Contábil de Clientes }\end{array}$ \\
\hline
\end{tabular}

Quadro 3: Fatores de Referência e Práticas de Gestão Estratégica de Custos

Fonte: adaptado de Cinquini e Tenucci (2006).

Essa proposta de consolidação das práticas de GEC em grupos de referência, apesar de útil para uma visão mais setorizadas por aspectos dos posicionamentos estratégicos das empresas, é passível de outros ordenamentos. Rocha (1999), no âmbito da construção da arquitetura do sistema de informações para a GEC, argumenta que as informações geradas pelos sistemas tradicionais não especificam as informações de fornecedores, clientes ou concorrentes, pois o foco está na identificação das variáveis ambientais, de forma passiva. Já as informações geradas pelo sistema de informação de gestão estratégica são de natureza diversa, sendo tal sistema composto por um conjunto adequado de subsistemas que captam os aspectos mais relevantes do processo estratégico. Para Rocha (1999) as informações podem ser divididas em dois grupos:

- Grupo 1: Relativas a clientes, fornecedores e concorrentes, que valorizam índices, quociente e outras mensurações específicas, tais como, custos de mudanças e determinantes de custos, entre outras. Elas buscam a agregação de valor para toda a cadeia, pressupõem o envolvimento, o comprometimento, a troca de informações e a interação gerencial entre todos os elos importantes da cadeia. Verifica-se, com isso, uma atuação mais ativa, indo além da identificação das oportunidades e ameaças;

- Grupo 2: Relativas a valor dos produtos e serviços, complementares ou não 
e custeio-alvo da cadeia de relacionamentos, reunidos de forma integrada e harmônica com clientes.

\section{ASPECTOS METODOLÓGICOS}

\subsection{CLASSIFICAÇÃO DA PESQUISA}

Tendo em vista o objetivo estabelecido, essa pesquisa classifica-se como descritiva, pois se limita a descrever a realidade do objeto de estudo. Dada a pretensão de que os resultados dessa pesquisa possam ser aplicados na solução de problemas que ocorrem nas empresas, caracteriza-se ela, quanto à natureza, como uma pesquisa aplicada De acordo com Hussey e Collins (2005, p. 27) "a pesquisa aplicada é aquela que foi projetada para aplicar suas descobertas a um problema específico."

Quanto à abordagem do problema, tem-se uma pesquisa qualitativa, dado que ela possibilita destacar a características do objeto da pesquisa que não seriam observadas por meio de um estudo quantitativo. A respeito disso, e segundo Gil (1999), o estudo é qualitativo, pois não são utilizadas técnicas estatísticas na elucidação da problemática.

\subsection{COLETA E ANÁLISE DOS DADOS}

A entrevista em profundidade foi a técnica principal de coleta de dados adotada no estudo. Segundo Malhorta (2001) a entrevista em profundidade é uma forma desestruturada e direta de se obter informações, mas é diferente do grupo de foco, pois é conduzida individualmente. Mason (1996) alerta que apesar da dificuldade de haver uma padronização nessa forma de condução de entrevistas, é importante manter um roteiro estruturado de forma a garantir que os principais focos da pesquisa sejam abordados.

A análise dos dados, face o objetivo do estudo, seguiu a abordagem qualitativa. A par das análises qualitativas, os dados foram apresentados na forma de tabelas, identificando-os de forma mais objetiva. Para Calvo (2004) a tabela é um quadro que resume um conjunto de observações, cujo objetivo é o de produzir uma impressão mais rápida e viva do fenômeno em estudo.

\subsection{CARACTERIZAÇÃO GERAL DA EMPRESA PESQUISADA}

A empresa estudada é uma sociedade limitada, cujos principais executivos estão ligados à família detentora da propriedade. Líder no setor de indústria química de adesivos, a empresa completou 61 anos de fundação em maio de 2009. Está classificada entre as 100 maiores empresas do estado do Rio Grande do Sul, sendo que em 2008 ocupou a $10^{a}$ posição entre as empresas mais internacionalizadas. Tais 
dados surgem da pesquisa realizada pelo Jornal Valor em parceria com a Sociedade Brasileira de Estudos de Empresas Transnacionais e da Globalização Econômica, com índice de internacionalização de 26,9\%, conforme destacado por Machado (2009).

A missão da empresa é entregar soluções inovadoras e integradas às cadeias de valor onde atua, gerando retornos superiores para todas as partes interessadas. Além do lucro como meio de crescimento a empresa também valoriza o comprometimento com a entrega de valor ao cliente, a liderança através de tecnologias diferenciadas e inovadoras, o comportamento ético e o desenvolvimento dos seus funcionários.

A empresa atua com cinco plantas no Brasil mais cinco unidades produtivas localizadas no exterior, a saber: Argentina, Colômbia, Chile, Peru e México. Esse conjunto forma uma adequada estrutura de produção e distribuição, oferecendo aos seus clientes locais e no exterior, soluções inovadoras. A estrutura estratégica e operacional da empresa está distribuída três unidades de negócio: Adesivos, Laminados e Produtos de Segurança.

A receita líquida anual média no triênio 2006/2008 atingiu a $\mathrm{R} \$ 220,1$ milhões, composto por $70 \%$ proveniente do mercado interno, uma participação de mercado situada na faixa de 11 a $20 \%$. No final de 2008, o corpo funcional totalizou 1.690 empregados, 673 deles admitidos durante o próprio ano. 0 entrevistado atualmente ocupa o cargo de gerente de controladoria; trabalha na empresa há oito anos e possui 15 de experiência na função. É graduado em ciências contábeis e administração de empresas. Especialização em controladoria e marketing, além do mestrado em finanças, completa o perfil da sua formação acadêmica.

\section{RESULTADOS DA PESQUISA}

A entrevista com o profissional do setor de controladoria da empresa ocorreu no mês de agosto de 2009, foi realizada na sede da empresa e desenvolvida em duas etapas. A primeira, com duração aproximada de uma hora, foi utilizada para esclarecer os objetivos e conteúdo básico da pesquisa e verificar os graus de transparência e confidencialidade exigidos pela empresa; nessa etapa também foi discutido e apresentado um exemplar preliminar do roteiro da entrevista. A segunda, utilizada para realização da entrevista propriamente dita, foi conduzidas em dois períodos de uma hora e meia cada, intercalados por um pequeno intervalo de 15 minutos. Mediante prévia concordância do respondente a entrevista foi gravada, possibilitando posterior análise detalhada das respostas.

A pesquisa foi realizada considerando os níveis operacional, tático e estratégico, envolvendo as formas de divulgação interna das informações contábeis e de custos, em cada nível, relacionadas à contabilidade geral, gerencial e estratégica. No âmbito da contabilidade financeira e de custos, as questões tratam da adequação do elenco e plano de contas e das demonstrações contábeis usuais, seus usuários e periodicidade de elaboração.

\subsection{ASPECTOS GERAIS DE ATUAÇÃO E DA GESTÃO ESTRATÉGICA DA EMPRESA}


As respostas oferecidas pelo entrevistado permitem traçar o perfil dos aspectos gerais que subsidiam a atuação da empresa. Foi identificado que a empresa atua em mercados de elevado nível de concorrência, predominando um misto de produção em massa e produção personalizada. O ciclo de vida dos produtos é classificado pelo entrevistado como médio, havendo um variado mix de produtos. Além dessas questões, tem-se também a caracterização de uso acentuado de tecnologias avançadas de produção forte restrição da concorrência quanto a aumento de preços.

No âmbito da gestão estratégica, em conformidade com as três estratégias genéricas de Porter (1989), o posicionamento estratégico central da empresa está na diferenciação de produtos, baseado na inovação. Isso fica claro com as afirmativas do entrevistado no sentido de que a direção da empresa privilegia e destina investimentos significativos na inovação e desenvolvimento de novos produtos e formação de profissionais com atuação direta em atividades de diferenciação. Entretanto, dada a multiplicidade de negócios (três unidades) e abrangência de atuação (presença internacional), a empresa tem também orientações estratégicas focadas na busca de liderança baseada em custos, o que corrobora o desenvolvimento teórico apresentado por Hansen e Mowen (2001), a empresa adota regularmente o desenvolvimento do planejamento estratégico como forma de direcionar organizadamente a estratégia da empresa. O BSC é um instrumento utilizado sistematicamente nesse processo, contando inclusive com indicadores a respeito de inovação e desenvolvimento, conforme apresentado no Quadro 5.

Outro aspecto estratégico destacado pelo entrevistado é quanto ao crescimento da empresa, ocorrido via aquisições e internacionalização da companhia. Além disso, a perseverante busca de soluções técnicas para os clientes e a oferta de novos produtos tem sido a estratégia raiz para firmar o conceito da marca.

\subsection{ASPECTOS DA CONTABILIDADE FINANCEIRA}

O plano de contas está estruturado para atender a legislação fiscal, inclusive na estrutura relacionada à contabilidade de custos. As contas de resultado, segundo sua natureza, estão agrupadas por centro de custo e consolidadas por unidades de negócio. Neste caso, o propósito é o monitoramento do resultado operacional em cada um desses níveis organizacionais. Existe um esforço de estruturar um plano de contas unificado, abarcando as unidades do exterior, o que facilitará a consolidação das informações também a nível corporativo.

O balanço patrimonial, a demonstração do resultado e a demonstração da mutação do patrimônio líquido são os relatórios contábeis de uso corrente pela empresa e divulgados aos diretores e gerentes de unidades de negócios com periodicidade mensal e anual. A demonstração do fluxo de caixa, de emissão mensal, é disponibilizada para o setor de tesouraria, subsidiando as atividades da gestão financeira.

A demonstração da necessidade de capital de giro é o relatório específico da gestão de valores circulantes, emitido mensalmente e distribuído para a diretoria e aos 
gerentes de unidade de negócios. Por essa demonstração acompanha-se a evolução das contas dos circulantes operacionais - ativos e passivos - e a necessidade de recursos para a sua cobertura financeira. A razão deste procedimento deve-se ao controle divisional do endividamento para financiar investimentos no giro. A contabilidade geral e de custos atende aos requisitos societários tradicionais e de gestão e avaliação econômico-financeira da empresa. Em relação ao custeio, a preocupação fundamental é a avaliação de estoques, com a utilização do método de custeio por absorção, e a utilização do custo-padrão como instrumento de precificação e controle.

\subsection{ASPECTOS DA CONTABILIDADE GERENCIAL}

No âmbito da contabilidade gerencial foram investigadas as práticas utilizadas no planejamento e controle, inclusive quanto à sua intensidade. Utilizou-se a escala de Likert de 6 pontos, cujos extremos situam-se entre [1] não utiliza e [6] planeja utilizar. Todas as respostas com referência à contabilidade gerencial foram dadas ao nível [4] "utiliza intensamente", para fins das seguintes questões centrais: (a) controle das operações, com informações de eficiência e qualidade dos processos executados; (b) custeio de produtos e de distribuição; (c) controle administrativo das unidades operacionais; (d) controle estratégico das unidades de negócios.

No emprego das técnicas de decisão e controle, a empresa informou o grau [4] para: (a) análise de margem de contribuição, suportada em relatório específico; (b) custeio departamental e por unidade de negócios, com destaque nas despesas com pesquisa e desenvolvimento, acompanhado pelo comitê de inovação; (c) custopadrão como ferramenta de controle do custo real, de determinação do preço de venda e de elaboração do controle orçamentário. O ponto de equilíbrio é de uso eventual e obteve grau [2], significando utilização apenas parcial.

\subsection{ASPECTOS DA GESTÃO ESTRATÉGICA DE CUSTOS}

Nesta parte do estudo é apresentado o resultado da investigação sobre o grau de utilização e dos benefícios percebidos com as diversas práticas de GEC (Quadro 4).

\begin{tabular}{|c|c|c|}
\hline Prática & Uso $^{*}$ & Benefício $^{* *}$ \\
\hline Análise do Custo Intangível & 3 & Não declarado $^{*}$ \\
\hline Análise dos Direcionadores de Custos & 4 & 5 \\
\hline Análise da Cadeia de Valor & 4 & 4 \\
\hline Análise do Custo do Ciclo de Vida & 1 & 1 \\
\hline Custeio Baseado em Atividades - ABC & 1 & 1 \\
\hline Gestão Baseada em Atividades - ABM & 1 & 1 \\
\hline Mensuração e Análise do Custo Ambiental & 4 & 5 \\
\hline Mensuração e Análise do Custo da Qualidade & 4 & 5 \\
\hline Análise do Custo dos Concorrentes & 3 & 1 \\
\hline Custo Meta & 1 & 1 \\
\hline Análise dos Custos Logísticos & 4 & 4 \\
\hline Análise do Custo Total de Uso e Propriedade (TCO) & 1 & 1 \\
\hline
\end{tabular}




\section{Custo Kaizen}

2

Quadro 4: Práticas, Usos e Benefícios da Gestão Estratégica de Custos

* Uso: [1]Não utiliza; [2]Utiliza parcialmente; [3]Utiliza; [4]Utiliza Intensamente; [5]Já utilizou e abandonou; [6]Planeja utilizar.

** Benefício obtido: [1] Nenhum; [2] Pouco; [3] Intermediário; [4] Elevado; [5] Muito elevado.

Algumas práticas foram assinaladas como não utilizadas e sem qualquer sinalização de provável uso futuro. São elas: (a) análises do custo do ciclo de vida; (b) custeio baseado em atividades - ABC; (c) gestão baseada em atividades - ABM; (d) custo meta; (e) análise do custo total de uso e propriedade.

Apesar de não totalmente esclarecido pelo entrevistado, a não utilização do custo total de uso e propriedade decorre do fato de a empresa ser fornecedora de produtos intermediários e não finais - essa é uma interpretação a ser melhor discutida na empresa visto que a situação argumentada não justifica a não utilização do TCO. Em relação ao uso das atividades como base de práticas específicas, seja no custeio $(A B C)$ ou na gestão $(A B M)$, há uma forte alegação da desfavorável relação custo $x$ benefício, um argumento bastante presente quando se investiga tais práticas.

Em relação ao custo meta, a expressiva utilização e satisfação quanto ao custo-padrão (utilizada intensamente e com benefícios elevados) é o principal argumento apresentado pelo entrevistado, o mesmo se aplicando com relação ao custo kaizen. Segundo o entrevistado isso é uma decorrência da predominância do procedimento da precificação realizada com base nos custos e não na concorrência, dado o posicionamento estratégico, na maioria dos casos, focado na liderança e inovação.

Quanto às práticas declaradas de utilidade e benefícios intensos, destaque foi dado aos direcionadores de custos, a cadeia de valor, o custo ambiental e custo da qualidade. Existe parceria com uma empresa italiana para a produção de laminados, com tecnologia ecoeficiente, proporcionando ganhos ambientais e de mercado. Neste sentido, a tecnologia é vista como importante direcionador de custos; além dela também há destaque ao expressivo uso da capacidade instalada.

A análise da cadeia de valor é preocupação da empresa, principalmente em relação aos requerimentos dos clientes e às parcerias com fornecedores. 0 placar de indicadores inclui dados sobre a inflação interna (materiais) e a avaliação de fornecedores. A empresa atua fortemente junto aos clientes visando encontrar soluções técnicas para o adequado uso do produto. Mesmo não havendo um explícito uso do $A B M$, o interesse com a rentabilidade e fidelização de clientes direciona a identificação, eliminação ou redução de atividades que não geram valor. Por fim, tem-se a análise dos custos dos concorrentes, cujo benefício está em nível bastante inferior ao benefício obtido. O entrevistado esclareceu, a esse respeito, que na realidade o procedimento limita-se a análise das demonstrações contábeis da empresa com as de seus principais concorrentes, com objetivo de acompanhar e comparar as evoluções de vendas e lucratividade.

\subsection{INDICADORES ESTRATÉGICOS - BSC}

A parte final da coleta e análise de dados envolveu, no âmbito da estrutura do BSC, a identificação de indicadores estratégicos.

O entrevistado indicou que o BSC é atualizado mensalmente e contém 28 indicadores, 
com as seguintes perspectivas: financeira (9), de clientes (4), de processos (9) e de aprendizado (6). Dez desses indicadores, transcritos no Quadro 5, são considerados pela empresa como estratégicos pois refletem suas metas de liderança tecnológica, de competitividade e de crescimento. Cabe ressaltar que no BSC atual não há indicadores de monitoramento de concorrentes.

\begin{tabular}{|c|c|c|}
\hline Indicador Estratégico & Meio de Avaliação & Perspectiva \\
\hline Rentabilidade Operacional & Lucro Operacional/Ativo Operacional & Financeira \\
\hline Grau de Endividamento & Dívidas com Bancos/Ativo Operacional & Financeira \\
\hline Vendas Externas & Receita Líquida Exportação / Rec. Líquida Total & Clientes \\
\hline Satisfação de Clientes & $\begin{array}{c}\text { Avaliação da Satisfação de Clientes, por meio } \\
\text { do cumprimento do prazo de entrega, defeitos, } \\
\text { devoluções, etc. }\end{array}$ & Clientes \\
\hline Uso de Capacidade & Capacidade Utilizada/Capacidade Instalada & Processos \\
\hline Ganhos c/idéias implantadas & $\begin{array}{c}\text { Ganhos em R\$ com as idéias implantadas (receitas } \\
\text { menos custos incrementais) }\end{array}$ & Processos \\
\hline Inovação e Desenvolvimento & Quantidade de Patentes registradas no Ano & Processos \\
\hline Índice de Fornecedores & $\begin{array}{c}\text { Avaliação de Fornecedores (tempo de entrega e } \\
\text { qualidade do material) }\end{array}$ & Processos \\
\hline $\begin{array}{l}\text { Prontidão de Ação dos } \\
\text { Recursos Humanos }\end{array}$ & Sucessão nos níveis de média e alta gerência & Aprendizado \\
\hline Índice de Clima Satisfação & $\begin{array}{c}\text { Pesquisa de Clima (absenteísmo e rotatividade de } \\
\text { pessoal) }\end{array}$ & Aprendizado \\
\hline
\end{tabular}

Quadro 5: Placar de Indicadores Estratégicos do BSC

Seguindo a tendência de dar maior ênfase nos indicadores não financeiros, observa-se que dos dez indicadores considerados estratégicos somente dois classificamse na perspectiva financeira, o mesmo ocorrendo com relação às perspectivas de clientes e aprendizado. Assim, a perspectiva mais destacada corresponde a processos, talvez um reflexo da busca pela melhoria contínua.

\subsection{RELAÇÃO ENTRE POSICIONAMENTO ESTRATÉGICO E PRÁTICAS DE GESTÃO DE CUSTOS}

Dado que a pesquisa centra-se na adoção de práticas de gestão estratégica de custos, e tendo em vista os fundamentos teóricos que justificaram o desenvolvimento de tais práticas, justifica-se aqui uma análise da relação entre o posicionamento estratégico da empresa pesquisada e as práticas de gestão por ela adotadas.

A partir das informações dadas pelo respondente, consultas ao site da empresa, e ao fato de ela ter atuação operacional com grande diversidade de negócios desenvolvidos com plantas estabelecidas em diversos países, tem-se como conclusão estar ela inserida em um mercado de alta intensidade concorrencial, ensejando a necessidade de informações diferenciadas para uma gestão eficaz. Caracterizamse assim as premissas que amparam e justificam o desenvolvimento das práticas de gestão de custos pesquisadas. Isso pode ser corroborado pelo estudo de Johnson e Kaplan (1987) e Guilding, Cravens e Tayles (2000). 
No aspecto do posicionamento estratégico, o declarado posicionamento de liderança em custos e liderança em diferenciação, adotados respectivamente em função de específicos segmentos de negócio da empresa, conforme declarado pelo respondente está em linha com os estudos de Porter (1989 e 2004). Não obstante esses aspectos, a adoção das práticas de gestão estratégica de custos, no caso desta empresa, não ocorre com a intensidade que é apresentada pela literatura correspondente. De fato, afora algumas aplicações parciais, com ênfase específica a situações especiais, o que caracteriza a gestão de custos da empresa é a preferência por aquelas práticas mais tradicionais, seja no âmbito do custeio (absorção), seja com foco no planejamento e controle (custo-padrão a nível departamental), seja no indicador de lucratividade (margem de contribuição). Tais práticas, segundo a literatura de custos, são práticas úteis e aplicáveis a uma realidade diferente do atual mercado de concorrência acirrada e da novas práticas operacionais e estratégicas adotadas para assegurar a continuidade dos negócios.

Diante de tal constatação, restringindo inclusive o estabelecimento da justificativa de uma possível relação e identificação entre as características estratégicas da empresa e a sua gestão estratégica de custos, é natural que surja uma instigação dada a aparente contradição que é verificada. 0 principal argumento apresentado pelo respondente centra-se na satisfação com o uso das práticas mais tradicionais dado que elas tem respondido às necessidades da gestão.

Além disso, crítica é efetuada pelo entrevistado à baixa relação custo $x$ benefício das práticas de GEC, complexidade de implantação e falta de pessoal familiarizado com elas. Segundo ele, esses fatores fazem com que a aplicação mais intensiva dessas práticas não seja uma questão prioritária na empresa. Com maior ou menor intensidade é esse o resultado encontrado em diversas pesquisas sobre essa temática, como aquelas apresentadas na Introdução desse artigo.

\section{CONCLUSÕES}

Este estudo mapeou as práticas de gestão e de gestão estratégica de custos, com o objetivo de identificar como uma empresa industrial, que atua em um mercado competitivo e global, valida os procedimentos e benefícios destacados pela literatura como necessários para alcançar a vantagem competitiva.

O trabalho atingiu seu objetivo ao relacionar o mundo real da empresa pesquisada com as principais práticas de gestão estratégica de custos mencionadas na literatura, enfatizando basicamente as utilizadas, as não utilizadas e as com perspectivas de uso. Dentro do que foi possibilitado apreender com o conteúdo das respostas do entrevistado procurou-se identificar aspectos específicos quanto à aplicabilidade e benefícios das práticas investigadas.

Constatou-se que mesmo com algumas limitações há uma cultura de gestão estratégica na empresa. Já quanto à aplicação das práticas de GEC é evidente que há ainda necessidade de evolução mais acentuada, apesar do sucesso dos negócios, conforme declarado pelo entrevistado, o que acaba por contrastar os argumentos da literatura. Com base no que é advogado pela literatura relacionada às práticas 
de GEC, pode-se observar o ainda forte uso do custo-padrão, em contraposição ao custo-meta e ao custo kaizen chama atenção, principalmente em função da reconhecida dificuldade para majoração de preços. 0 mesmo se aplica à necessidade de uma abordagem mais ampla da análise de custos da cadeia de valor e de custos dos concorrentes. Essas duas últimas práticas são colocadas em destaque, pois elas refletem a intensidade com que a literatura recomenda a análise externa de custos. Também foi possível identificar a falta de planos para adoção de algumas das práticas analisadas, tais como o $A B C$, o $A B M$, o custo-meta e o custo de uso e propriedade. Parece que a não identificação objetiva dos possíveis benefícios ainda está bloqueando tal adoção.

Apesar de toda a ênfase da literatura quanto às necessidades de adoção das práticas de GEC, o que reflete uma visão normativa dos pesquisadores consultados, os achados desta pesquisa corroboram os resultados de aplicações apenas parciais encontrados em outras pesquisas semelhantes, destacadas na introdução deste estudo. Portanto, comparativamente aos conceitos da literatura mais recente sobre gestão de custos parece que ainda há muito a evoluir na sua validação e utilização pelas empresas.

Como novos estudos nessa temática, sugere-se avançar na pesquisa da possível relação entre a adoção das práticas de GEC e o desempenho de empresas. Acreditase que estudos comparativos pré e pós-adoção das práticas possam quantificar mais objetivamente os benefícios dessa adoção. Além disso, e mais especificamente nos casos de baixa adesão a tais práticas, sugere-se estudos de casos em profundidade na busca de identificar causas mais concretas para essa ausência. Nestes estudos de casos sugere-se a abordagem da Teoria da Contingência, a exemplos dos estudos iniciais de Rodrigues e Reinaldo (2004) e Aguiar e Frezatti (2007. 


\section{REFERÊNCIAS}

AGUIAR, Andson B.; FREZATTI, Fábio. Sistema de controle gerencial e contextos de processo de estratégia: contribuição da teoria da contingência. In: CONGRESSO USP DE CONTROLAdORIA E CONTABILIDADE, 7, 2007, São Paulo. Anais... FEA/USP, São Paulo, 2007.

BACIC, Miguel Juan. Escopo da gestão estratégica de custos em face das noções de competitividade e de estratégia empresarial. 1994. Disponível em: www.eco. unicamp.br/abc/l.html. Acesso em: 15 jun. 2009.

BOWHILL, Bruce; LEE, Bill. The incompatibility of standard costing systems and modern manufacturing. Journal of Applied Accounting Research, v.6, 3, p.1-24, 2002.

CALVO, M. C. M. Estatística descritiva. Florianópolis: UFSC, 2004.

CINQUINI, Lino e TENUCCI, Andrea. Strategic management accounting: exploring distinctive features and links with strategy. 2006. Disponível em: http://mpra. ub.uni.muenchen.de/212/. Acesso em: 20 jul 2009.

DE ZOYSA, Anura; HERATH, S.Kanthi. Standard costing in Japanese firms. Industrial Management \& Data Systems, v.107, 2, p. 271-283, 2007.

DEKKER, Henri; SMIDT, Peter. A survey of the adoption and use of target costing in Dutch firms. International Journal of Production Economic, v. 84, 3, p.293-305, 2003.

FRANCO, Hilário. A contabilidade na era da globalização. São Paulo: Atlas, 1999.

GIL, A. C. Métodos e técnicas de pesquisa social. 5.ed. São Paulo: Atlas, 1999.

GOMES, Josir S. Tópicos contemporâneos em contabilidade. RBC, 91, p.79, 1995.

GREENWALD, Bruce; KAHN, Judd. A estratégia competitiva desmistificada. Rio de Janeiro: Elsevier, 2006.

GUILDING, Chris; CRAVENS, Karen S.; TAYLES, Mike. An international comparison of strategic management accounting practices. Management Accounting Research, v.11, 1, p.113-135, 2000. 
HANSEN, Don R.; MOWEN Maryanne M. Gestão de custos: contabilidade e controle. São Paulo: Pioneira Thomson Learning, 2001.

HUSSEY, Roger; COLLINS, Jill. Pesquisa em administração: um guia prático para alunos de graduação e pós-graduação. 2.ed. Porto Alegre: Bookman, 2005.

IUDÍCIBUS, Sérgio. A gestão estratégica de custos e sua interface com a contabilidade gerencial e teoria da contabilidade. CFC, RBC, 100, p. 30-31, jul/ago 1996.

JOHNSON, H. Thomas; KAPLAN, Robert S. Relevance lost: the rise and fall of management accounting. Boston: HBSP, 1987.

JOHNSON, H. Thomas. Relevance regained: from top-down control to bottom-up empowerment. New York: Free Press, 1992.

KAPLAN, R. S.; ANDERSON, S. Custeio baseado em atividade e tempo. Rio de Janeiro: Elsevier, 2007.

KAPLAN, R.S.; NORTON, D.P. A estratégia em ação: balanced scorecard. Rio de Janeiro: Campus, 1997.

MACHADO, Débora G; SOUZA, Marcos A. Análise das relações entre a gestão de custos e a gestão do preço de venda. Universo Contábil, v.2, 1, p. 42-60, 2006.

MACHADO, Fernanda N. Estratégias de internacionalização e seus resultados. 2009. XXX f. Dissertação (Mestrado em Administração) Universidade Federal do Rio Grande do Sul, Porto Alegre, 2009.

MALHORTA, Naresh K. Pesquisa de marketing: uma orientação aplicada. Porto Alegre, Bookman, 2001.

MARCONI, M. A.; LAKATOS, E. M. Metodologia científica. São Paulo: Atlas, 2008.

MARTINS, Eliseu. Contabilidade de custos. 9.ed. São Paulo: Atlas, 2008.

MASON, JENNIFER. Qualitative researching. London, Saje Publications, 1996.

MIOTTO, Genossi R. Análise da gestão estratégica de custos no setor de aviação comercial brasileiro. 2007. Dissertação (Mestrado em Ciências Contábeis) Unisinos, São Leopoldo, 2007.

MOLINARI, Sarah K.R.; GUERREIRO, Reinaldo. Teoria da contingência e contabilidade gerencial: um estudo de caso sobre o processo de mudança na controladoria do Banco do Brasil. In: CONGRESSO USP DE CONTROLADORIA E CONTABILIDADE, 4, 2004, São Paulo. Anais... FEA/USP, São Paulo, 2004. 
MONDEN, Yasuhiro. Cost reduction systems: target costing and kaizen costing. New York: Productivity Press, 1995.

MORELLI, Beata; WIBERG, Carl-Joachim. The standard costing system at SKF. Accounting \& Finance Master Thesis Göteborg University, 2002. Disponível em: http://www.handels.gu.se:81/epc/archive/00002757/01/gbs_thesis_2002_48.pdf. Acesso em: 05 nov. 2009.

MOTTA, R. A busca da competitividade nas empresas. Revista de Administração de Empresas. São Paulo: v. 35, 01, p. 12-16, 1995.

MURRAY, A.I. A contingency view of Porter's generic strategies. Academy of Management Review, v. 13, 3, p. 390-400, 1988.

NAKAGAWA, M. ABC - custeio baseado em atividades. São Paulo: Atlas, 1994.

PEREIRA, E.; ARIMA, C.G.; KOBAYASHI, A.K. A integração do sistema de contabilidade de custos aos sistemas de apoio à decisão. Base, v.1, 1, p.13-24, 2004.

PORTER, Michael E. Estratégia competitiva: técnicas para análise de indústrias e da concorrência. Rio de Janeiro: Elsevier, 2004.

. Vantagem competitiva: criando e sustentando um desempenho superior. Rio de Janeiro: Campus, 1989.

PRADO, Lauro J. Série empresarial: Guia de custos. E-Book: $1^{\circ}$ julho 2004, versão 2. Disponível em: < www.widebiz.com.br/ebooks/prado/custos>. Acesso em: 14 jul. 2009.

QUESADO, Patrícia R.; RODRIGUES, Lúcia L. A gestão estratégica de custos em grandes empresas portuguesas. Revista Ibero Americana de Contabilidad de Gestion, v.1, 10, p.121-143, 2007.

RATTRAY, C.J.; LORD, B.R.; SHANAHAN, Y.P. Target costing in New Zealand manufacturing firms. Pacific Accounting Review, v.19, 1, p.68-83, 2007.

RECKZIEGEL, V.; SOUZA, M.A.; DIEHL, C.A. Práticas de gestão adotadas por empresas estabelecidas nas Regiões Noroeste e Oeste do Paraná. RBGN, v.9, 23, p.14-27, 2007.

ROCHA, Welington. Contribuição ao estudo de um modelo conceitual de sistema de gestão estratégica. 1995. Tese (Doutorado em Controladoria e Contabilidade) Universidade de São Paulo. São Paulo, FEA/USP, 1999.

SHANK, John K.; GOVINDARAJN, Vijay. Gestão Estratégica de Custos - A nova 
ferramenta para a vantagem competitiva. Rio de Janeiro: Campus, 1995.

SLAGMULDER, Regine; COOPER, Robin. Interorganizational costing, part 1. Cost Management, v.7, 6, p. 14-21, set./out. 2003.

SOUZA, M. A. Práticas de contabilidade gerencial adotadas por subsidiárias brasileiras de empresas multinacionais. 2001. Tese (Doutorado em Controladoria e Contabilidade) Universidade de São Paulo. São Paulo, FEA-USP, 2001.

, ZANELLA, F. C., NASCIMENTO, A. M. Utilização do custo-meta por empresas brasileiras como estratégia de gestão. Revista Contabilidade e Finanças - USP São Paulo, 39, p.33-46, 2005

SOUZA, M. C. A. F.; BACIC, M.J.; RABELO, F.M. Flexibilidade, exploração de interrelações e aprendizado organizacional: referências para a GEC. 1995. Disponível em: libdigi.unicamp.br/document/?down=130. Acesso em 15 Jun 2009.

SULAIMAN, M. , AHMAD, N.N.N.; ALWI, N. M. Is standard costing obsolete? Empirical evidence from Malaysia. Managerial Auditing Journal, v. 20, 2, p.109-124, 2005.

SULAIMAN, M., AHMAD, N.N.N.; ALWI, N. M. Management accounting practices in selected Asian countries. Managerial Auditing Journal, v. 19, 4, p. 493-508, 2004.

VAN DER MERWE, Anton. Debating the principles: $A B C$ and its dominant principle of work. Cost Management, v.23, 5, p. 20-28, Sep/Oct 2009.

WAWERU, N. M.; HOQUE, Z.; ULIANA, E. A survey of management accounting practices in South Africa. International Journal of Accounting, Auditing and Performance Evaluation, v.2, 3, p. 226 - 263, 2005.

WRIGHT, Peter; KROLL, Mark J.; PARNELL, John. Administração estratégica. São Paulo: Atlas, 2000. 


\section{ENDEREÇO DOS AUTORES:}

\section{Marcos Antonio Souza}

Universidade do Vale do Rio dos Sinos

Centro de Ciências Econômicas, Área de Conhecimento e Aplicação de Contabilidade, Custos e Finanças.

Av. Unisinos, 950 - Cristo Rei

São Leopoldo, RS - Brasil

93022-000

\section{Élio Justo Silva}

Justo Assessoria \& Contabilidade Ltda.

Av. Tomas Edson, 3046 - Scharlau

Sao Leopoldo, RS - Brasil

93125-140

Nestor Pilz

Universidade do Vale do Rio dos Sinos

Centro de Ciências Econômicas, Área de Conhecimento e Aplicação de Contabilidade, Custos e Finanças.

Av. Unisinos, 950 - Cristo Rei

São Leopoldo, RS - Brasil

93022-000 